\title{
Arbuscular Mycorrhiza-Induced Shifts in Foliar Metabolism and Photosynthesis Mirror the Developmental Stage of the Symbiosis and Are Only Partly Driven by Improved Phosphate Uptake
}

\author{
Rabea Schweiger, Markus C. Baier, and Caroline Müller \\ Department of Chemical Ecology, Bielefeld University, Universitätsstraße 25, 33615 Bielefeld, Germany
}

Submitted 9 May 2014. Accepted 14 August 2014.

In arbuscular mycorrhizal (AM) plants, the plant delivers photoassimilates to the arbuscular mycorrhizal fungus (AMF), whereas the mycosymbiont contributes, in addition to other beneficial effects, to phosphate $\left(\mathrm{PO}_{4}{ }^{3-}\right)$ uptake from the soil. Thereby, the additional fungal carbon (C) sink strength in roots and improved plant $\mathrm{PO}_{4}{ }^{3-}$ nutrition may influence aboveground traits. We investigated how the foliar metabolome of Plantago major is affected along with the development of root symbiosis, whether the photosynthetic performance is affected by $\mathrm{AM}$, and whether these effects are mediated by improved $\mathrm{PO}_{4}{ }^{3-}$ nutrition. Therefore, we studied $\mathrm{PO}_{4}{ }^{3-}$-limited and $\mathrm{PO}_{4}{ }^{3-}$-supplemented controls in comparison with mycorrhizal plants at 20,30 , and 62 days postinoculation with the AMF Rhizophagus irregularis. Foliar metabolome modifications were determined by the developmental stage of symbiosis, with changes becoming more pronounced over time. In a wellestablished stage of mature mutualism, about $60 \%$ of the metabolic changes and an increase in foliar $\mathrm{CO}_{2}$ assimilation were unrelated to the significantly increased foliar phosphorus $(P)$ content. We propose a framework relating the time-dependent metabolic changes to the shifts in $\mathrm{C}$ costs and $P$ benefits for the plant. Besides P-mediated effects, the strong fungal $C$ sink activity may drive the changes in the leaf traits.

Associations between vascular plants and arbuscular mycorrhizal fungi (AMF) of the phylum Glomeromycota are among the most ancient and widespread mutualisms in terrestrial ecosystems, thus having a high ecological significance (Parniske 2008; Strack et al. 2003). The mutualistic interaction is characterized by a bidirectional exchange of nutrients. Whereas the autotrophic plant delivers photoassimilates to the obligate biotrophic fungus, the fungal partner, in return, improves the water and nutrient - particularly phosphorus ( $\mathrm{P}$, as orthophosphate, $\mathrm{PO}_{4}{ }^{3-}$ ) - uptake of the plant (Karandashov and Bucher 2005; Smith 1982). $\mathrm{PO}_{4}{ }^{3-}$ is an essential mineral nutrient for plants and limits plant growth in many natural habitats. As the diffusion capacity of $\mathrm{PO}_{4}{ }^{3-}$ in soils is very low and plants take up

Corresponding author: C. Müller: E-mail: caroline.mueller@uni-bielefeld.de

* The $\boldsymbol{e}$-Xtra logo stands for "electronic extra" and indicates that one supplementary figure and one supplementary table are published online.

(C) 2014 The American Phytopathological Society the available $\mathrm{PO}_{4}{ }^{3-}$ rapidly, $\mathrm{PO}_{4}{ }^{3-}$-depleted zones emerge around the plant roots (Rausch and Bucher 2002). Here, root-colonizing AMF are able to extend their extra-radical mycelia beyond these depletion zones, thereby reaching and mobilizing $\mathrm{PO}_{4}{ }^{3-}$ sources not available to plant roots and, thus, significantly contribute to the $\mathrm{P}$ supply of their host plant (Karandashov and Bucher 2005). Indeed, the $\mathrm{PO}_{4}{ }^{3-}$ uptake pathway via mycorrhizal hyphae can be the dominant route for $\mathrm{P}$ uptake in arbuscular mycorrhizal (AM) symbioses, even when plant growth or total $\mathrm{PO}_{4}{ }^{3-}$ uptake are not affected by AM (Smith et al. 2004). Hence, AMF can act as biofertilizers and reduce fertilizer application rates in agriculture (Gianinazzi et al. 2010).

Although the colonizing AMF are spatially restricted to the root compartment, they may influence various traits of the systemic aboveground plant parts. Indeed, positive effects of AM on apparent plant parameters like shoot growth and photosynthesis are well-described, whereas knowledge on AMF-mediated changes, particularly of secondary metabolites in aerial plant tissues, is quite limited (Toussaint 2007). However, AMF may modulate the chemical composition of systemic plant tissues for the following reasons. As, in functional AM, up to $20 \%$ of plant-fixed assimilates are delivered to the AMF for maintenance and growth (Parniske 2008), the mycobiont imposes a strong carbon (C) sink to the plant, thereby likely influencing $\mathrm{C}$ allocation patterns at the whole-plant level. Moreover, as $\mathrm{P}$ is not only part of various plant compounds (nucleic acids, phospholipids, enzymes) but, also, a key component in plant energy metabolism, chemical activation, signal transduction cascades, and enzymatic regulations (Karandashov and Bucher 2005; Rausch and Bucher 2002), the symbiotically improved plant $\mathrm{PO}_{4}{ }^{3-}$ nutrition and distribution through the vascular system may also influence shoot metabolism, acting upon various biochemical pathways of primary and secondary metabolites.

Whereas many studies addressed local chemical changes in the particular interaction tissues of mycorrhizal roots (Bi et al. 2007; Liu et al. 2014; Schliemann et al. 2008), only a few studies characterized AMF effects on leaf chemistry (Copetta et al. 2006; Kapoor et al. 2007; Toussaint et al. 2007; Zubek et al. 2012). Most of these studies focused on certain target metabolites, thereby potentially missing unexpected metabolic changes, as revealed, for example, by Fester and associates (2011) and Schweiger and associates (2014a). To cover a large part of the plant chemical composition, metabolomics techniques should thus be applied (Bundy et al. 2009; Fiehn 2002). Using a comparative approach, we recently showed that a substantial establishment of the AMF Rhizophagus irregularis 
[(Blaszk., Wubet, Renker \& Buscot) C. Walker \& A. Schüßler comb. nov.] (Glomales, Glomeromycota) (Schüßler and Walker 2010), indeed, influenced up to $15 \%$ of the polar leaf metabolome of different plant species and that metabolic response patterns were highly plant species-specific (Schweiger et al. 2014a).

The outcome of foliar metabolic changes mediated by the AM establishment in the plant probably strongly depends on the developmental stage of the mutualism, as, from the plant's point of view, both the costs (in terms of carbohydrates delivered to the AMF) and the benefits (in terms of $P$ gained via the AMF) change over the progress of interaction. Up to a certain developmental stage, the $\mathrm{C}$ sink capacity, which is imposed by an immense gain of fungal biomass, should trigger the interaction, as long as the extra-radical hyphae do not reach the areas beyond the $\mathrm{PO}_{4}{ }^{3-}$ depletion zones. Thenceforward, the improved $\mathrm{P}$ nutrition gained by the extended extra-radical mycelium will influence the aboveground metabolome changes. Although improvement of $\mathrm{P}$ nutrition is unambiguously one of the major effects of AMF on plants, only few studies addressed whether changes in plant growth, metabolites, and photosynthesis are solely driven by this nutritional effect or whether there are additional AMF impacts beyond the pure $\mathrm{P}$ improvement (Toussaint 2007).

Thus, the current study was designed to determine plant traits in an AM development-depending manner, in particular, i) how the foliar metabolome is modulated by AM, ii) whether photosynthetic performance is affected by AM, and iii) in how far these effects are solely P-mediated. Therefore, we conducted a comprehensive environmental metabolomics approach using Plantago major as the model species, as its metabolome with and without mycorrhization by $R$. irregularis is already wellcharacterized (Pankoke et al. 2013; Schweiger et al. 2014a). We compared the polar foliar metabolomes and photosynthetic performances of nonmycorrhizal plants grown under $\mathrm{PO}_{4}{ }^{3-}$ limitation and mycorrhizal plants at different time points after inoculation $(20,30$, and 62 days postinoculation [dpi]). Addi-
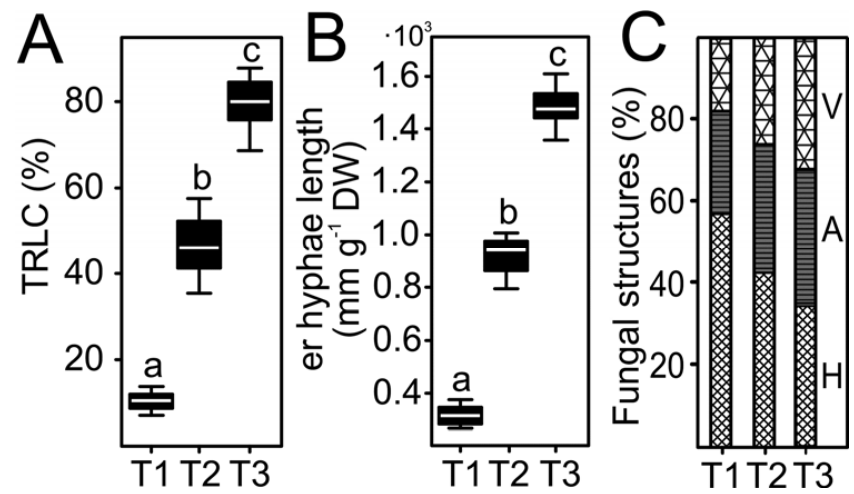

Fig. 1. Establishment and quantitative characteristics of the Plantago major-Rhizophagus irregularis root interaction (arbuscular mycorrhizal plants) at the morphological level at three different time points (days postinoculation [dpi]): T1, $20 \mathrm{dpi}$; T2, $30 \mathrm{dpi}$; T3, 62 dpi. Box-Whisker plots represent the median (horizontal line), the interquartile range (box), and the whiskers (extending to the 5 and $95 \%$ percentile, respectively). A, Total root length colonization (TRLC), differing significantly between arbuscular mycorrhizal (AM) plants harvested at the three time points (KruskalWallis test, $X^{2}=25.83, d f=2, P<0.001$ ). B, Length of extra-radical (er) hyphae related to dry weight (DW) of the growth substrate, differing significantly between AM plants harvested at the three time points (analysis of variance, $\left.\mathrm{F}_{2,27}=859.00, P<0.001\right)$. Different letters $(\mathrm{a}, \mathrm{b}, \mathrm{c})$ indicate significant differences in a post hoc Kruskal mc (A) and Tukey honest significant difference $(\mathrm{B})$ test $(P<0.05)$. C, Mean proportion of fungal hyphae $(\mathrm{H})$, arbuscules $(\mathrm{A})$, and vesicles $(\mathrm{V})$ within the colonized parts of $P$. major roots at the three time points; $n=10$ biological replicates per time point. tionally, a $\mathrm{PO}_{4}{ }^{3-}$-supplemented nonsymbiotic control was included in the study to discriminate purely $\mathrm{P}$-mediated from those AM effects in which $\mathrm{P}$ is not involved. We show that the foliar metabolic changes are highly dependent on the developmental stage of the mutualistic plant-fungus interaction. Moreover, these changes and the coinciding increase in the photosynthetic rate are only partly driven by the improved $\mathrm{P}$ supply under mycorrhizal conditions. Therefore, a theoretical framework is proposed relating the time-dependent metabolic changes to the shifts in $\mathrm{C}$ costs and $\mathrm{P}$ benefits for the plant.

\section{RESULTS}

\section{Foliar $\mathbf{P}$ increases similarly} under $\mathrm{PO}_{4}{ }^{3-}$ supplementation and mycorrhization.

This study was designed to characterize foliar metabolome modulations and the photosynthetic performance of $P$. major under mycorrhization by $R$. irregularis in a time-dependent manner and to assess to what extent the effects are due to an improved $\mathrm{PO}_{4}{ }^{3-}$ uptake gained due to this symbiosis. Therefore, we grew nonmycorrhizal plants under $\mathrm{PO}_{4}{ }^{3-}$-limited conditions (NM), nonmycorrhizal $\mathrm{PO}_{4}{ }^{3-}$-supplemented plants (PNM), and arbuscular mycorrhizal plants grown in soil under $\mathrm{PO}_{4}{ }^{3-}$-limited conditions $(\mathrm{AM})$ and conducted measurements on aerial parts at 20, 30, and $62 \mathrm{dpi}$ (T1, T2, and T3, respectively). In symbiotic roots, both root colonization with fungal structures (total root-length colonization [TRLC]) (Fig. 1A) as well as the length of extra-radical hyphae (Fig. 1B) in the substrate steeply increased over time, reaching about $80 \%$ TRLC at $62 \mathrm{dpi}$. In parallel, the proportion of arbuscules and vesicles relative to hyphae increased (Fig. 1C). Some extra-radical spores were detected at T3. Taken together, T1 represents a young AM stage with minor fungal root colonization and $\mathrm{T} 2$ an intermediate stage characterized by a developing symbiotic interaction. At T3, a mature, well-established AM was found, as deduced from the high TRLC and the occurrence of many vesicles and first spores at this last time point. No fungal structures were observed in the nonsymbiotic treatment groups.

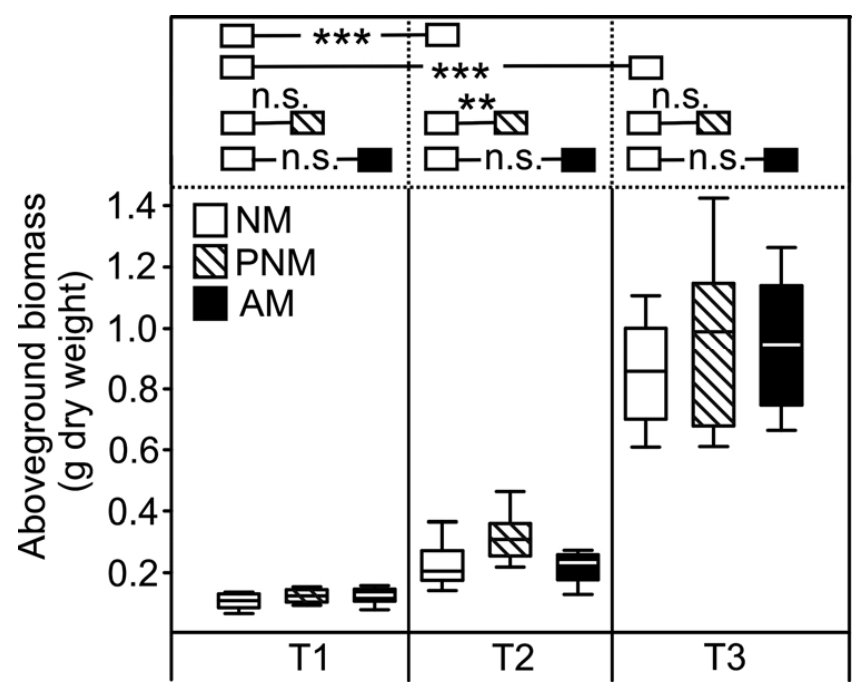

Fig. 2. Total aboveground biomass of nonmycorrhizal phosphate $\left(\mathrm{PO}_{4}{ }^{3-}\right)$ limited (NM), nonmycorrhizal $\mathrm{PO}_{4}{ }^{3-}$-supplemented (PNM), and arbuscular mycorrhizal (AM) Plantago major plants at three different time points (days postinoculation [dpi]) after inoculation of AM plants with Rhizophagus irregularis: T1, $20 \mathrm{dpi}$; T2, $30 \mathrm{dpi}$; T3, 62 dpi. Box-Whisker plots represent the median (horizontal line), the interquartile range (box), and the whiskers (extending to the 5 and $95 \%$ percentile, respectively). Results of manually set orthogonal pair-wise contrasts of a generalized linear model are given at the top (n.s. $=$ not significant; $* *=P<0.01$, $* * *=P<0.001$ ); $n=10$ biological replicates per treatment group and time point. 
Irrespective of the plant treatment, all plants gained significant aboveground biomass, except for a slight but significant higher shoot biomass in PNM compared with NM plants at T2 (Fig. 2), as indicated by a significant Time $\times$ Treatment interaction (generalized linear model [GLM], gamma error structure and identity link function; Null model: residual $d f=89$, residual deviance $=69.83$; factor Time: $d f=87$, deviance $=6.04, P\left[X^{2}\right]<$ 0.001 ; factor Treatment: $d f=85$, deviance $=5.58, P\left[X^{2}\right]=0.021$; Time $\times$ Treatment: $d f=81$, deviance $\left.=4.90, P\left[X^{2}\right]=0.022\right)$. Along with the gain in biomass, the numbers of leaves and inflorescences per plant individual increased over time (leaves: 3 to 6 at T1, 5 to 7 at T2, 7 to 9 at T3; inflorescences: 1 to 2 at $\mathrm{T} 1,1$ to 4 at T2, 3 to 7 at T3) but were independent of the treatment (Kruskal-Wallis tests within each time point; leaves, T1: $X^{2}=1.42, d f=2, P=0.491 ; \mathrm{T} 2: X^{2}=3.48, d f=2, P=$ $0.175 ; \mathrm{T} 3: X^{2}=3.12, d f=2, P=0.210$; inflorescences, T1: $X^{2}$ $=1.84, d f=2, P=0.399 ; \mathrm{T} 2: X^{2}=3.41, d f=2, P=0.182 ; \mathrm{T} 3$ : $\left.X^{2}=1.44, d f=2, P=0.486\right)$. At T1, the inflorescences showed first buds, whereas at the later time points (T2, T3), buds, flowers, and also some unripe fruits (at T3) were found. The numbers of buds, flowers, and fruits were similar between the treatment groups within each time point (data not shown). Thus, confounding effects of differences in leaf developmental stages or plant reproductive status between treatment groups on metabolic measurements could be excluded to the greatest possible extent under the growth conditions applied.

Total leaf $\mathrm{P}$ content was significantly affected by time and marginally by the treatment (GLM, gamma error structure and log link function; Null model: $d f=89$, deviance $=65.86$; factor Time: $d f=87$, deviance $=53.19, P\left[X^{2}\right]<0.001$; factor Treatment: $d f=85$, deviance $\left.=51.12, P\left[X^{2}\right]=0.087\right)$. It increased by both $\mathrm{PO}_{4}{ }^{3-}$ supplementation and mycorrhization at $\mathrm{T} 3$ but not at $\mathrm{T} 1$ or only marginally at $\mathrm{T} 2$, as indicated by a significant Time $\times$ Treatment interaction $(d f=81$, deviance $=$ 46.40, $P\left[X^{2}\right]=0.025$ ) (Fig. 3A). Moreover, the $\mathrm{P}$ contents of PNM and AM plants were both equally higher compared with NM plants at T3 (Fig. 3A), confirming that the PNM control properly simulated the increase in total $\mathrm{P}$ of $\mathrm{AM}$ compared with NM plants at this time point. Foliar carbon (C) and nitro- gen $(\mathrm{N})$ contents significantly differed in the plants between time points, with the lowest values at the last harvest, but were unaffected by treatment (Fig. 3B), as indicated by elimination of this factor during model simplification (GLM, Gaussian error structure and identity link function) for both $\mathrm{C}$ (Null model: $d f=89$, deviance $=128.45$; factor Time: $d f=87$, deviance $=106.08, F=9.18, P<0.001)$ and $\mathrm{N}$ content (Null model: $d f=89$, deviance $=61.50$; factor Time: $d f=87$, deviance $=40.30, F=22.88, P<0.001)$.

\section{$\mathrm{PO}_{4}{ }^{3-}$ supplementation and mycorrhizal effects on the foliar metabolome change} over the course of plant and symbiotic development.

The polar foliar metabolome of $P$. major was analyzed by a dual-platform metabolomics approach using targeted metabolite profiling of primary metabolites (carbohydrates, organic acids, amino acids, sugar alcohols) via gas chromatography coupled with mass spectrometry (GC-MS) as well as untargeted metabolic fingerprinting via ultra-high performance liquid chromatography (uHPLC) coupled with time of flight (ToF)MS. With this combination of approaches, our goal was not to identify all metabolites but to broadly cover the foliar metabolome, thereby revealing representative patterns of metabolic changes related to $\mathrm{PO}_{4}{ }^{3-}$ supplementation and mycorrhization, respectively. Moreover, basic primary metabolites and characteristic secondary metabolites (aucubin, verbascoside) of $P$. major were specifically targeted, as they may give insight in underlying mechanisms and could be important for ecological interactions with herbivores and pathogens. In total, we found 2,078 metabolic features (30 per GC-MS, and 2,048 per uHPLC-ToF-MS), of which 18 (16 per GC-MS, two per uHPLC-ToF-MS) could be identified (Supplementary Table $\mathrm{S} 1$ ). To quantify the influence of nonsymbiotic $\mathrm{PO}_{4}{ }^{3-}$ supplementation as well as mycorrhization on individual foliar metabolic features, $\log _{2}$-fold changes of feature intensities of PNM and AM plants, respectively, compared with the common NM control were calculated. A cluster heatmap of these fold changes revealed that effects on the foliar metabolome clearly changed over time, with groups being clustered within time
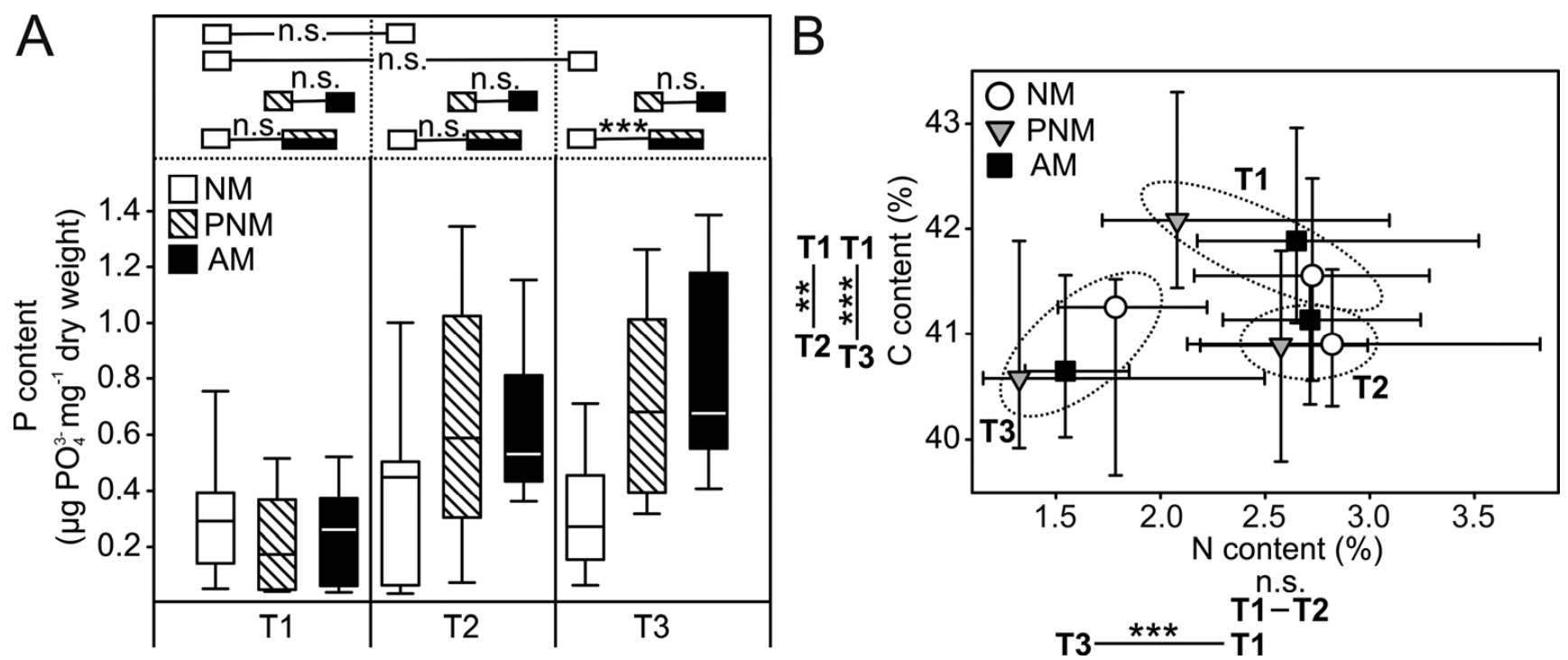

Fig. 3. Total foliar phosphorus $(\mathrm{P})$, carbon $(\mathrm{C})$, and nitrogen $(\mathrm{N})$ contents of nonmycorrhizal phosphate $\left(\mathrm{PO}_{4}{ }^{3-}\right)$-limited (NM), nonmycorrhizal $\mathrm{PO}_{4}{ }^{3-}$-supplemented (PNM), and arbuscular mycorrhizal (AM) Plantago major plants at three different time points (days postinoculation [dpi]) after inoculation of AM plants with Rhizophagus irregularis: T1, 20 dpi; T2, 30 dpi; T3, 62 dpi. A, Total leaf P contents $\left(\mathrm{PO}_{4}{ }^{3-}\right.$ of mineralized leaves) as Box-Whisker plots representing the median (horizontal line), the interquartile range (box), and the whiskers (extending to the 5 and $95 \%$ percentile, respectively). Results of manually set orthogonal pair-wise contrasts of a generalized linear model (GLM) are given at the top (n.s. = not significant; *** $=P<0.001$ ). B, Total leaf C and $\mathrm{N}$ contents given as medians (symbols) and interquartile ranges ( 25 and $75 \%$ percentiles). Results of GLM treatment contrasts (T1 as reference factor level) are given along each axis $(* *=P<0.01, * * *=P<0.001) ; n=10$ biological replicates per treatment group and time point. 
points (Supplementary Fig. S1). As depicted in our cluster heatmap, at T1 some sugars (fructose, glucose, and sucrose) were increased in PNM as compared with NM plants, whereas we found a decrease of several organic acids from the citric acid cycle (succinic acid, malic acid, citric acid, and isocitric acid) in AM compared with NM plants at T3. In addition to these basal descriptions of decreases and increases of feature intensities, we defined stringent selection criteria for a metabolic feature to be 'modulated,' namely a significant difference (Mann Whitney- $U$ test, $P<0.05$ ) and a certain fold change (decrease in metabolite pool size: $<0.67,<-0.58$ on $\log _{2}$ scale; increase in pool size: $>1.5,>0.58$ on $\log _{2}$ scale) between the metabolites of the treatment groups (PNM and AM) versus the control (NM). Applying these criteria, the number of modu- lated features increased over time for both the PNM and AM treatment (Fig. 4). At T2, four (AM) to six (PNM) times more metabolites were decreased than increased in metabolite pool sizes, whereas at T3, about two times more features were increased than decreased by $\mathrm{PO}_{4}{ }^{3-}$ supplementation and mycorrhization, respectively (Fig. 4).

\section{The foliar metabolome responses to mycorrhization} are only partly mimicked by direct $\mathrm{PO}_{4}{ }^{3-}$ supplementation.

Whereas some metabolic features were modified in the same direction (decrease or increase) in $\mathrm{PO}_{4}{ }^{3-}$-supplemented and mycorrhizal plants compared with the common NM control, others were modulated differentially regarding the absolute fold changes or the direction of change of metabolic pool
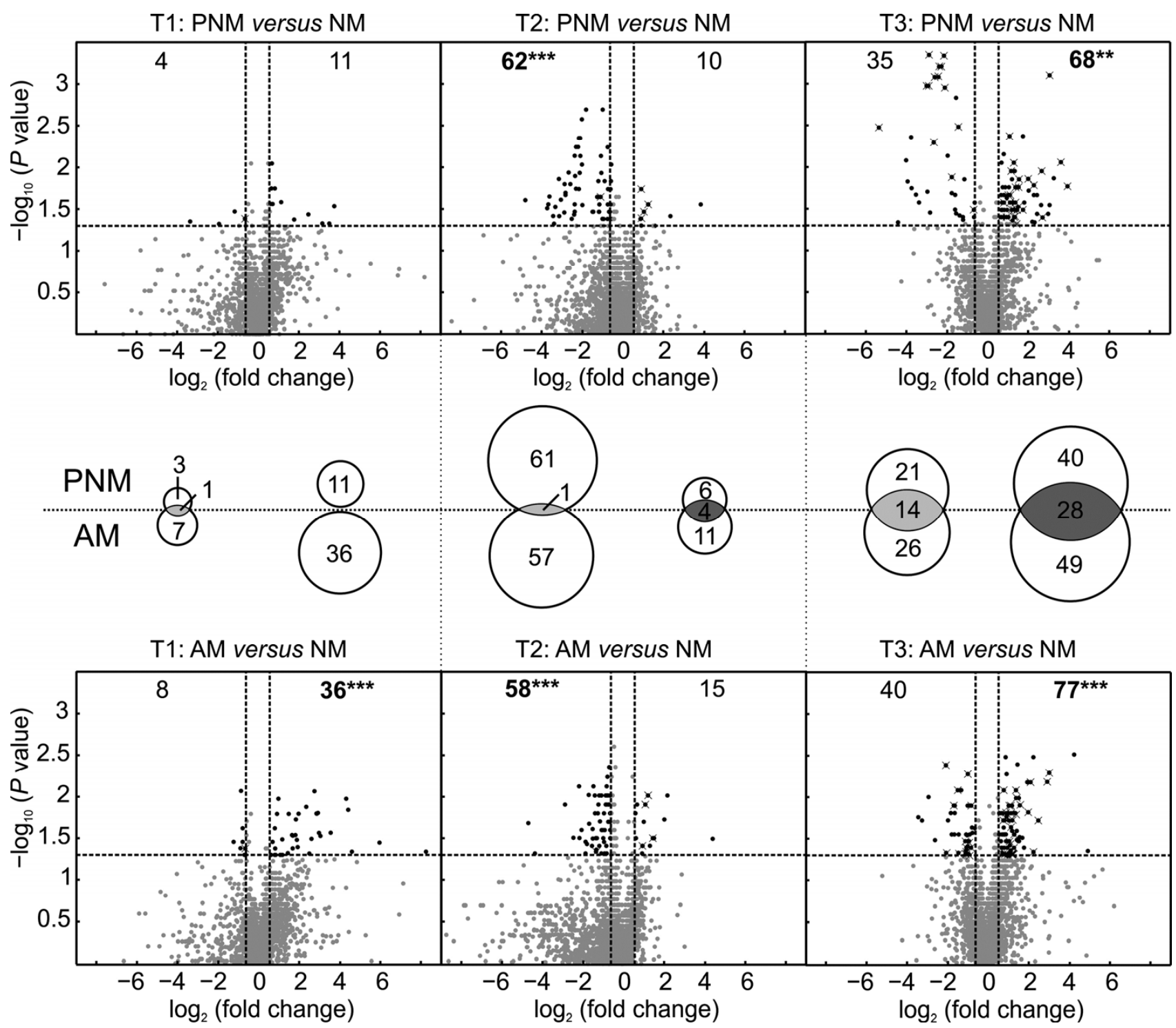

Fig. 4. Volcano plots depicting foliar metabolic features modulated in nonmycorrhizal phosphate $\left(\mathrm{PO}_{4}{ }^{3-}\right)$-supplemented (PNM, at the top) and arbuscular mycorrhizal (AM, at the bottom) Plantago major plants, respectively, as compared with the common nonmycorrhizal $\mathrm{PO}_{4}{ }^{3-}$-limited (NM) control plants at three different time points (days postinoculation [dpi]) after inoculation of AM plants with Rhizophagus irregularis: T1, 20 dpi (left); T2, 30 dpi (center); T3, 62 dpi (right). Features showing a significant difference between groups (Mann Whitney- $U$ test, unadjusted $P<0.05$ ) and a certain mean fold change (decrease in metabolite pool size: $<0.67,<-0.58$ on $\log _{2}$ scale, left; increase in pool size: $>1.5,>0.58$ on $\log _{2}$ scale, right in respective panel) are indicated as black symbols outside the cut off-lines. After $P$ adjustment according to Benjamini and Hochberg, no significant differences remained. For each comparison, the numbers of features with decreased versus increased pool sizes (according to the defined criteria above) are given and it is indicated whether these significantly differed from a uniform distribution $\left(X^{2}\right.$ tests, $*^{*}=P<0.01$, *** $\left.=P<0.001\right)$. Within each time point (T1 to T3) and for each direction of change (decrease or increase), the overlap of leaf chemical responses (i.e., number of features modulated by both $\mathrm{PO}_{4}{ }^{3-}$-supplementation and mycorrhization as compared with the common NM control; light gray for decrease, dark gray for increase in metabolite pool size) as well as the treatment-specific responses are presented as area-proportional Venn/Euler diagrams (middle row) and the corresponding features are indicated by crosses in the volcano plots; $n=9$ to 10 biological replicates per treatment group and time point. 
sizes. According to the criteria for modulation mentioned above, there were only a few metabolic features modulated by both $\mathrm{AM}$ and $\mathrm{PO}_{4}{ }^{3-}$ supplementation at $\mathrm{T} 1$ and $\mathrm{T} 2$ (Fig. 4, middle row). At T3, however, about $40 \%$ of the foliar metabolome responses to AM (AM versus NM comparison) overlapped with those to $\mathrm{PO}_{4}{ }^{3-}$ supplementation (PNM versus NM comparison). Because T3 is the time point at which the foliar P contents of PNM and AM plants were similarly and significantly increased as compared with the common NM control (Fig. 3A) and there were no confounding treatment effects on plant biomass (Fig. 2), the overlapping metabolic responses compared with the common NM control group can be interpreted as mainly P-mediated. However, the majority of the foliar metabolome responses to $\mathrm{PO}_{4}{ }^{3-}$ supplementation and mycorrhization (about 60\%) were treatment-specific (Fig. 4, middle row), i.e., only found after $\mathrm{PO}_{4}{ }^{3-}$ supplementation (PNM versus NM comparison) or after mycorrhization (AM versus NM comparison).

\section{Photosynthetic performance is enhanced}

by AM symbiosis at a late stage of symbiosis development.

Foliar chlorophyll fluorescence and gas exchange were measured at a defined leaf of each plant at the three time points (T1 to T3), using a separate batch of plants. TRLC and extra-radical hyphae lengths of the AM plants used for these measurements were similar to those of AM plants harvested in parallel for chemical analyses (data not shown). Neither the maximum quantum yield $\mathrm{F}_{\mathrm{v}} / \mathrm{F}_{\mathrm{m}}\left(\mathrm{T} 1\right.$ : Kruskal-Wallis test, $X^{2}=$ $1.10, d f=2, P=0.578 ; \mathrm{T} 2$ : analysis of variance [ANOVA], $F_{2,27}=1.74, P=0.195 ;$ T3: ANOVA, $\left.F_{2,27}=0.07, P=0.936\right)$ (Fig. 5A) nor the effective quantum yield of photosystem II $\Delta \mathrm{F} / \mathrm{F}_{\mathrm{m}^{\prime}}$ (T1: ANOVA, $F_{2,27}=0.89, P=0.421 ; \mathrm{T} 2$ : KruskalWallis test, $X^{2}=3.26, d f=2, P=0.196$; T3: ANOVA, $F_{2,27}=$ $1.24, P=0.307$ ) (Fig. 5B) were affected by $\mathrm{PO}_{4}{ }^{3-}$ supplementation or AM, indicating that the plants of all groups were healthy and not photo-inhibited (Björkman and Demmig 1987). The apparent electron transport rate (ETR) did not differ between the treatment groups at T1 and T3 (ANOVA, T1: $F_{2,27}=0.72, P=0.495$; T3: $F_{2,27}=1.05, P=0.363$ ) but was significantly lower in AM compared with PNM plants at T2 (Kruskal-Wallis test: $X^{2}=7.74, d f=2, P=0.021$ ) (Fig. 5C). The $\mathrm{CO}_{2}$ assimilation rate $\mathrm{A}$ (T1: Kruskal-Wallis test, $X^{2}=$ 1.03, $d f=2, P=0.598$; T2: ANOVA, $F_{2,27}=5.48, P=0.010$; T3: ANOVA, $F_{2,27}=11.83, P<0.001$ ) (Fig. 5D) and the transpiration rate E (T1: Kruskal-Wallis test, $X^{2}=4.00, d f=2, P=$ 0.136 ; T2: ANOVA, $F_{2,27}=5.30, P=0.012$; T3: ANOVA, $F_{2,27}=$ $6.84, P=0.004$ ) (Fig. 5E), respectively, were significantly higher in AM compared with PNM plants at T2 and signifi-

Fig. 5. Parameters of foliar photosynthetic performance of nonmycorrhizal phosphate $\left(\mathrm{PO}_{4}{ }^{3-}\right)$-limited $(\mathrm{NM})$, nonmycorrhizal $\mathrm{PO}_{4}{ }^{3-}$-supplemented (PNM), and arbuscular mycorrhizal (AM) Plantago major plants at three different time points (days postinoculation [dpi]) after inoculation of AM plants with Rhizophagus irregularis: T1, 20 dpi (left); T2, 30 dpi (center); T3, 62 dpi (right). Data are given as Box-Whisker plots representing the median (horizontal line), the interquartile range (box), and the whiskers (extending to the 5 and 95\% percentile, respectively). Different letters (a, b) indicate significant differences between treatments within each time point according to post hoc Tukey honest significant difference tests (following an analysis of variance) or Kruskal mc tests (following a KruskalWallis test $)(P<0.05)$. A, Maximum quantum yield of photosystem II (PS II) of dark-adapted leaves $\left(\mathrm{F}_{\mathrm{v}} / \mathrm{F}_{\mathrm{m}}\right)$. B, Effective quantum yield of PS II $\left(\Delta \mathrm{F} / \mathrm{F}_{\mathrm{m}^{\prime}}\right)$ at a photosynthetic active radiation (PAR) of approximately 200 $\mu \mathrm{mol} \mathrm{m} \mathrm{m}^{-2} \mathrm{~s}^{-1}$. C, Apparent electron $\left(\mathrm{e}^{-}\right)$transport rate (ETR) at PAR $\approx 200$ $\mu \mathrm{mol} \mathrm{m} \mathrm{m}^{-2} \mathrm{~s}^{-1}$. D, $\mathrm{CO}_{2}$ assimilation rate (A) at PAR $=200 \mu \mathrm{mol} \mathrm{m} \mathrm{m}^{-2}$. $\mathbf{E}$, Transpiration rate $(\mathrm{E})$ at PAR $=200 \mu \mathrm{mol} \mathrm{m}^{-2} \mathrm{~s}^{-1} \cdot n=10$ biological replicates per treatment group and time point.

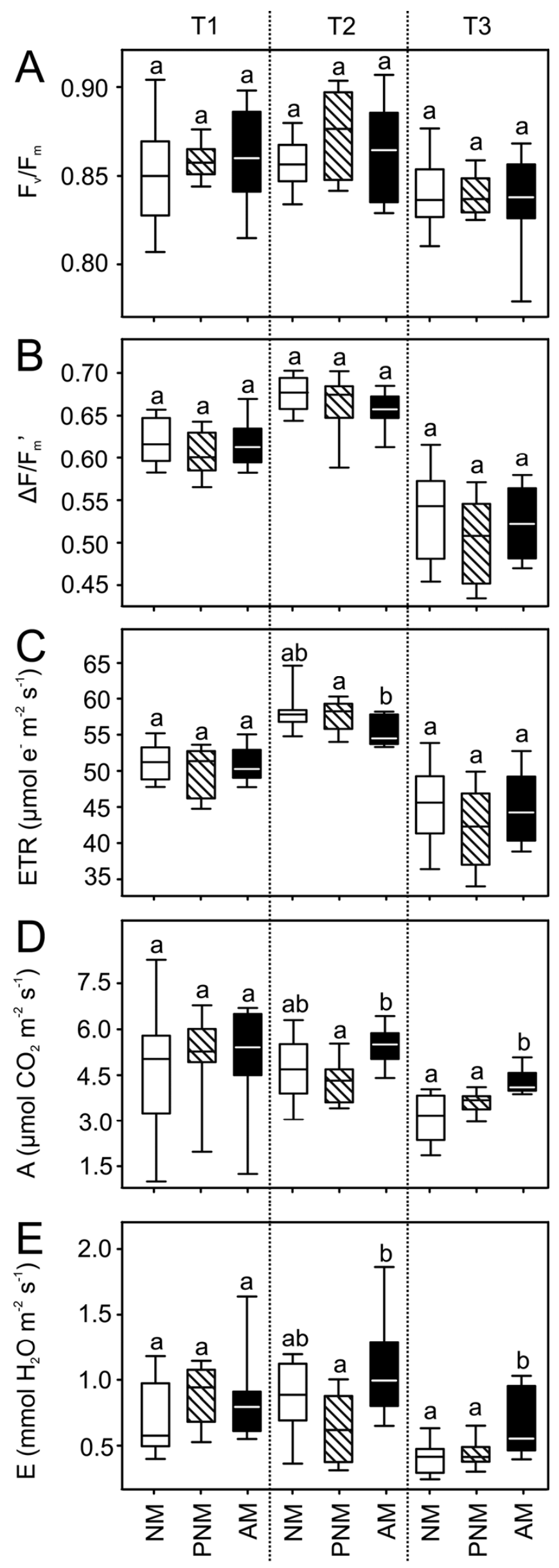

Vol. 27, No. 12, 2014 / 1407 
cantly higher in AM compared with PNM and NM plants at $\mathrm{T} 3$, pointing to $\mathrm{AM}$-specific effects on these traits that are independent of direct mineral $\mathrm{PO}_{4}{ }^{3-}$ supplementation.

\section{DISCUSSION}

Our study revealed that the foliar metabolome of $P$. major is modified by root colonization with the rapidly and extensively colonizing AMF species $R$. irregularis in a time-dependent manner. The changes became more pronounced along with the morphological establishment, i.e., the physiological integration of the AMF and functioning of the symbiosis (Figs. 4 and 5). Noteworthy, the developmental stages in terms of plant biomass (Fig. 2), leaf number, and reproductive status were comparable between NM and AM plants at the three time points of harvest and, thus, plant responses to AM were not confounded by growth effects under the defined conditions applied. In particular, the $\mathrm{PO}_{4}{ }^{3-}$ supply was high enough to ensure that $\mathrm{NM}$ plants had no severe syndromes of $\mathrm{PO}_{4}{ }^{3-}$ deficiency, whereas AM development was possible and $\mathrm{PO}_{4}{ }^{3-}$ uptake increased under AM conditions. Nevertheless, the distinct metabolic changes observed across different stages of AM colonization development suggest that the factors driving these responses of the plant metabolism go along with AM establishment and functioning, as proposed by our theoretical framework (Fig. 6). Since plants of all treatment groups had comparable numbers of inflorescences increasing in parallel to the aboveground biomass over time (Fig. 2), the relative sink strength of reproductive plant tissues can be assumed to be constant across treatments and over time. As both the intra- and extra-radical fungal mycelia significantly expanded over time (Fig. 1A and B), thereby probably competing with plant sink tissues for $\mathrm{C}$, the costs for the plant due to the fungal $\mathrm{C}$ demand likely increased, leading to higher $\mathrm{C}$ fluxes to $\mathrm{AM}$ roots compared with $\mathrm{C}$ allocations in NM plants (Fig. 6). This may explain the decrease of many foliar metabolic features observed under AM conditions at T2

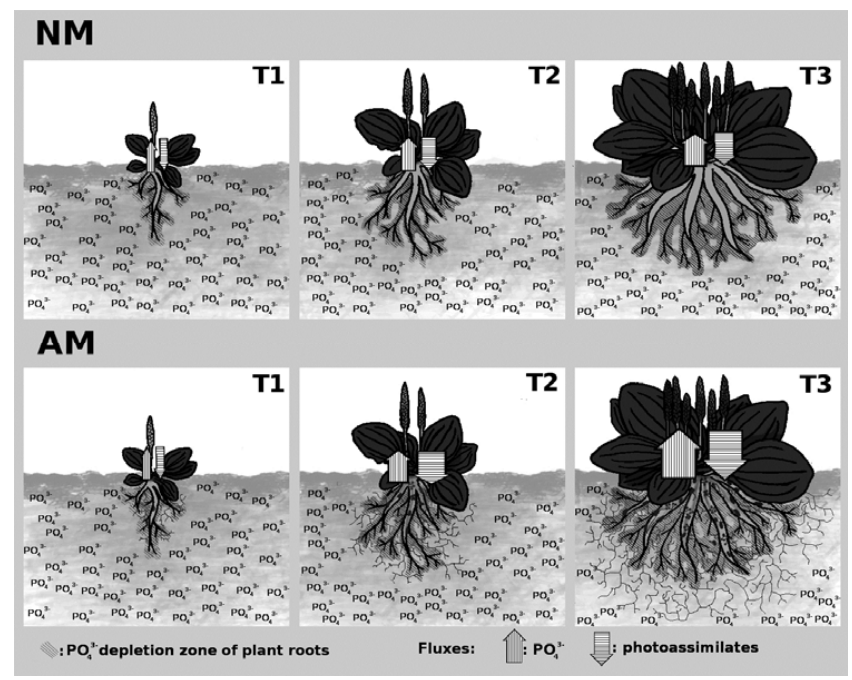

Fig. 6. Proposed framework describing the postulated fluxes of phosphate $\left(\mathrm{PO}_{4}{ }^{3-}\right)$ and photoassimilates in nonmycorrhizal $\mathrm{PO}_{4}{ }^{3-}$-limited (NM, at the top) and arbuscular mycorrhizal (AM, at the bottom) Plantago major plants at three different time points (days postinoculation, dpi) of establishment of the arbuscular root symbiosis with Rhizophagus irregularis in the AM plants: T1, $20 \mathrm{dpi}$; T2, $30 \mathrm{dpi}$; T3, 62 dpi. The numbers of leaves and inflorescences at each time point correspond to the median numbers of these organs found in the experiment. Widths of the arrows indicate the flux intensities of $\mathrm{PO}_{4}{ }^{3-}$ (up arrow) and photoassimilates (down arrow), respectively. Hatched areas represent the $\mathrm{PO}_{4}{ }^{3-}$ depletion zones of the plant roots. The extra-radical fungal mycelia are depicted as fine lines around the roots.
(Fig. 4), when the colonizing AMF probably gained much $\mathrm{C}$ to expand and maintain its hyphal network (Fig. 1). At this time point, $\mathrm{P}$ contents were already slightly but not significantly increased by AM (Fig. 3A). With the intra-radical sites of nutrient exchange, i.e., arbuscules, becoming more frequent and functionally mature (Fig. 1C) and with the extra-radical hyphal network extensively spreading (Fig. 1B), the contribution of the mycobiont to plant $P$ nutrition may increase (Fig. 6), resulting in elevated foliar P contents in AM compared with NM plants at T3 (Fig. 3A). The activation and enhancement of previously $\mathrm{P}$-limited processes and the likewise increased photosynthetic $\mathrm{CO}_{2}$ assimilation (Fig. 5D) may explain the higher pool sizes of many plant metabolic features in AM than in NM plants at this time point (Fig. 4). Whereas another study revealed that the $\mathrm{C}$ allocation dynamics between the mycorrhizal partners depend on $\mathrm{C}$ (light supply) and $\mathrm{P}$ availabilities in general (Olsson et al. 2010), our study adds further evidence that the development of the symbiosis itself and the accompanying time-dependent changes in $\mathrm{C}$ cost and $\mathrm{P}$ benefit for the plant drive whole-plant resource allocation patterns. Likewise, root transcripts and metabolites were shown to change along with the establishment of the mycorrhizal association (Brechenmacher et al. 2004; Harrison and Dixon 1993; Liu et al. 2003).

To focus on specific AM effects on the foliar metabolome and photosynthesis in a mature plant-AMF interaction, in the current study, T3 (62 dpi) was considered the optimal time point, as the fungal colonization was well-established (Fig. 1). Moreover, at this time point, the AM was likely beneficial for both partners, as indicated by the foliar $\mathrm{P}$ gain in AM compared with NM plants (Fig. 3A) and the occurrence of many fungal vesicles and first spores proving fungal differentiation (Fig. 1C). The specific AM-mediated responses of plant traits observed at this time point fit well with other studies. Increases of foliar P contents by AM are long noticed and were similarly described in various plant species (Black et al. 2000; Karagiannidis et al. 2012; Liu et al. 2014; Schweiger et al. 2014a; Stribley et al. 1980). Elevated pool sizes of many $P$. major foliar metabolic features at $62 \mathrm{dpi}$ with $R$. irregularis have been likewise reported recently (Schweiger et al. 2014a). Specifically, the decrease of organic acids of the citric acid cycle at T3 seems to be a common plant response, at least of dicotyledonous species, to AM, as it has already been found in five dicotyledons, including P. major (Fester et al. 2011; Schweiger et al. 2014a), but not in the monocot Poa annua (Schweiger et al. 2014a). Moreover, concordantly to our results (Fig. 5), increased photosynthetic rates due to AM have been revealed in various plant species, including different Fabaceae species and spring wheat (Poaceae) (Kaschuk et al. 2009; Zhang et al. 2012). The elevated photosynthetic performance of AM plants at a late stage of symbiosis development may be interpreted either as a result of the improved nutrient supply, as adaptation to compensate for the additional fungal $\mathrm{C}$ demand, or both (Kaschuk et al. 2009). The fact that foliar P (Fig. 3A) but not $\mathrm{N}$ contents (Fig. 3B) were increased by AM indicates that, if at all, $\mathrm{P}$ but not $\mathrm{N}$ nutrition may be important in this context.

To discriminate P-mediated from other, nonnutritional AM effects in a valid manner, three criteria, as proposed by Baas and Lambers (1988), have to be met. Under the experimental conditions of the current study, these criteria were met at T3: i) AM plant roots were well-colonized by AMF (Fig. 1), ii) plants of different treatment groups were equal in size and similar in their developmental stage (Fig. 2), and iii) PNM and AM plants had similar foliar P contents (Fig. 3A). Additionally, only at this time point, the foliar $\mathrm{P}$ contents were significantly increased by $\mathrm{PO}_{4}{ }^{3-}$ supplementation and mycorrhiza- 
tion, respectively (Fig. 3A), thereby allowing quantification of the contribution of the improved leaf $\mathrm{P}$ status of AM plants to the metabolic changes observed. At this time point, most metabolic changes in $P$. major (e.g., decrease of organic acids of the citric acid cycle) were independent of the present $P$ level and, thus, of the AM-mediated improved P contents, since they differed to a large extent between AM and PNM compared with NM plants (visible in the low overlap of metabolites [Fig. 4]). Similarly, studies on certain foliar target metabolites in different plant species reported that the inductions of these metabolites mediated by AM were not solely the effect of improved $\mathrm{P}$ nutrition (rosmarinic and caffeic acids in Ocimum basilicum [Toussaint et al. 2007], essential oils in Origanum sp. [Khaosaad et al. 2006], artemisin in Artemisia апnиa [Kapoor et al. 2007]). In contrast, AM-mediated alterations in $\mathrm{C}$ partitioning between the major carbohydrate pools in cucumber were shown to be predominantly P-mediated (Black et al. 2000). Like for the majority of foliar metabolic features of $P$. major, the increase in photosynthetic gas exchange found at T3 in the current study was not P-mediated, as it was not elevated in PNM plants (Fig. 5D and E), indicating that it is not simply a result of an elevated $\mathrm{P}$ availability. This finding is in agreement with a meta-analysis on Fabaceae species showing that not only nutrient stimulation but, also, sink stimulation plays a role in AM effects on plant photosynthesis (Kaschuk et al. 2009). Moreover, improved water uptake rates under AM conditions may have allowed AM plants of $P$. major to open their stomata longer as compared with NM plants, which would also result in increased $\mathrm{CO}_{2}$ assimilation capacities paralleled by increased transpiration rates, as observed (Fig. 5D and E). In contrast, in cucumber, the increase of photosynthesis under AM conditions was ascribed to P nutritional effects (Black et al. 2000). Both the non-P nutritional AM effects on several metabolic features and on photosynthetic gas exchange of $P$. major may be driven by additional symbiosis-related factors. For example, the strong $\mathrm{C}$ sink strength of the AMF mycelium may have influenced the $\mathrm{C}$ allocation patterns at the whole-plant level. Furthermore, signaling compounds like phytohormones, which play a role in the establishment and maintenance of the mutualistic interaction (irrespective of $\mathrm{P}$ nutrition), may affect the foliar metabolome and photosynthetic performance (Martín-Rodríguez et al. 2011; Shaul-Keinan et al. 2002; Toussaint 2007).

In summary, our study revealed that pool sizes of diverse foliar metabolic features changed in different directions (decreases and increases) along with the establishment of the AM mutualism. Thus, the AM developmental stage may be decisive for the outcome and quality of plant interactions with various organisms, including other plants of the same or different species, herbivores, pathogens, and even members of the third trophic level, which are influenced by the specific plant chemical composition. Indeed, the pronounced shifts in AM-mediated effects along AM development may partly explain the high variation found in the impact of AM on herbivores, even of the same feeding guild (Koricheva et al. 2009). Moreover, we show that both the foliar metabolism and photosynthesis are not just a direct function of an improved $\mathrm{P}$ nutrition but that the plant-AMF interaction is more complex, including also non-P nutritional effects. Further studies are needed to resolve the nature of these non-nutritional AM effects and to quantify the $\mathrm{C}$ costs and $\mathrm{P}$ benefits for the plant in relation to plant $\mathrm{C}$ allocation patterns.

\section{MATERIALS AND METHODS}

\section{Plant cultivation, fertilizer and mycorrhizal treatment.}

Plantago major L. (Plantaginaceae) seeds (Blauetikett Bornträger GmbH, Offstein, Germany) were surface-sterilized with $70 \%$ ethanol and $2 \%$ sodium hypochloride and were then soaked for $2 \mathrm{~h}$ in distilled water. Seeds were transferred to a 3:2 mixture of leached swelling clay ( $\mathrm{pH} 9.6,0.9 \mathrm{~g}$ of salt content per liter; Fibo ExClay, Lamstedt, Germany) and quartz sand (particle size: 0.1 to $0.5 \mathrm{~mm}$; Quarzwerke $\mathrm{GmbH}$, Frechen, Germany) and were incubated in the dark at $4^{\circ} \mathrm{C}$. After 3 days, they were transferred to a climate chamber $\left(20^{\circ} \mathrm{C}, 16 \mathrm{~h}\right.$ of light and $8 \mathrm{~h}$ of dark, 60 to $70 \%$ relative humidity, Osram fluora lamps, L 36W/77; Osram, Munich, Germany) and were piqued into small pots $(5 \mathrm{~cm}$ diameter) after 15 days. All plants were watered thrice weekly with the same volume per pot and were fertilized twice a week with increasing volumes of a $1 / 2$ strength modified Hoagland solution (Hoagland and Arnon 1950). One liter of this solution contained $2.5 \mathrm{ml}$ of 1 $\mathrm{M} \mathrm{Ca}\left(\mathrm{NO}_{3}\right)_{2}, 2.5 \mathrm{ml}$ of $1 \mathrm{M} \mathrm{KNO}_{3}, 1 \mathrm{ml}$ of $1 \mathrm{M} \mathrm{MgSO}_{4}, 1.5$ $\mathrm{ml}$ of $0.1 \mathrm{M} \mathrm{KH}_{2} \mathrm{PO}_{4}$ (adjusted at day 41 as discussed below), $5 \mathrm{ml}$ of $0.01 \mathrm{M} \mathrm{Fe}(\mathrm{III})$-citrate, and $1 \mathrm{ml}$ of the following micronutrients: $1 \mathrm{mM} \mathrm{H}_{3} \mathrm{BO}_{3}, 0.2 \mathrm{mM} \mathrm{NiCl}_{2}, 1 \mathrm{mM} \mathrm{ZnSO}_{4}, 0.2 \mathrm{mM}$ $\mathrm{MnCl}_{2}, 0.5 \mathrm{mM} \mathrm{CuSO}, 0.2 \mathrm{mM} \mathrm{CoCl}_{2}$, and $0.2 \mathrm{mM}$ $\mathrm{Na}_{2} \mathrm{MoO}_{4}$. Seedlings were transferred to 2-liter pots with a 3:2 swelling clay and quartz sand mixture 41 days after sowing and were randomly assigned to one of the following treatment groups. Arbuscular mycorrhizal (AM) plants were inoculated with $200 \mathrm{ml}$ of a fungal sand inoculum ( $\mathrm{pH} \mathrm{7}$; Inoq $\mathrm{GmbH}$, Schnega, Germany) of the generalist fungus Rhizophagus irregularis (Blaszk., Wubet, Renker \& Buscot) C. Walker \& A. Schüßler comb. nov. (Glomales, Glomeromycota) (Schüßler and Walker 2010). The inoculum was mixed with the upper two thirds of the substrate and seedlings were placed inside. To assess the extent to which plant responses to mycorrhization are due to the improved $\mathrm{PO}_{4}{ }^{3-}$ uptake under symbiosis, two types of nonmycorrhizal controls $\left(\mathrm{NM}=\mathrm{PO}_{4}{ }^{3-}\right.$-limited control; $\mathrm{PNM}=\mathrm{PO}_{4}{ }^{3-}$-supplemented control) were included. To assure the same microbial setting except for AMF, NM and PNM plants received $200 \mathrm{ml}$ sterilized $R$. irregularis inoculum and $30 \mathrm{ml}$ of a microbial wash obtained from the inoculum before sterilization by filtrating a washing of it through a $20 \mu \mathrm{m}$ sieve (Retsch, Haan, Germany). AM plants received the same amount of water instead. Whereas NM and AM plants were grown under $\mathrm{PO}_{4}{ }^{3-}$-limited conditions resembling low-P soils facilitating the establishment of a sufficient $\mathrm{AM}$ in the respective plants (i.e., $0.3 \mathrm{ml} 0.1 \mathrm{M} \mathrm{KH}_{2} \mathrm{PO}_{4}$ per 1 of fertilizer), $\mathrm{PNM}$ plants received higher levels of $\mathrm{PO}_{4}{ }^{3-}\left(1 \mathrm{ml}\right.$ of $\left.0.1 \mathrm{M} \mathrm{KH}_{2} \mathrm{PO}_{4}\right)$ from day 41 ( $0 \mathrm{dpi}$ ) on. Preliminary tests revealed that this adjustment of the fertilizer $\mathrm{PO}_{4}{ }^{3-}$ component resulted in total foliar P levels comparable to AM plants and, thus, was sufficient to simulate the improved $\mathrm{PO}_{4}{ }^{3-}$ uptake of $\mathrm{AM}$ compared with NM plants. The other fertilizer components remained constant and equal between the treatment groups. Forty pots per treatment group were placed in a randomized block design. At pot height, the mean photosynthetic active radiation (PAR) was $208 \mu \mathrm{mol} \mathrm{m}{ }^{-2} \mathrm{~s}^{-1}$.

For chemical analyses of leaves, 10 plants per treatment (NM, PNM, AM) and time point (dpi) were harvested at 20 (T1), 30 (T2), and 62 dpi (T3), respectively. The time points were based on preliminary tests that revealed that, at these time points, important, reproducible stages of the plant-fungus interaction are shown; at T1, minor fungal root colonization is established, followed by a steep increase through T2 and reaching a high level at T3. For each harvest, the leaves of the youngest third of ten plants per treatment group were cut in the early afternoon and were weighed, the metabolism was immediately quenched in liquid $\mathrm{N}_{2}$, and samples were frozen at $-80^{\circ} \mathrm{C}$. Leaves were lyophilized and milled, and the leaf powder distributed for several chemical analyses (discussed below). The remaining ten plants per group were used for measurements of photosynthetic performance (discussed below). 
After harvest and photosynthetic measurements, the roots of all plants were washed and representative subsamples were bleached $\left(10 \% \mathrm{KOH}, 15 \mathrm{~min}, 95^{\circ} \mathrm{C}\right)$, were acidified $(1 \% \mathrm{HCl}$, $5 \mathrm{~min}$, at room temperature [RT]), were stained (one part $0.4 \%$ trypan blue [Sigma-Aldrich, Steinheim, Germany] and 40 parts of 2:1:2 lactic acid/glycerine/ $\mathrm{H}_{2} \mathrm{O}, 48 \mathrm{~h}$ at RT), and were conserved (4:2:1 lactic acid/glycerine $/ \mathrm{H}_{2} \mathrm{O}, 4^{\circ} \mathrm{C}$ in the dark). TRLC (\%) was determined by counting at least 200 intersects per sample, using the grid-line intersect method (Giovannetti and Mosse 1980). Within the colonized root parts, specific fungal structures (hyphae, arbuscules, vesicles) were counted separately. Lengths of extra-radical hyphae were determined as previously described, with some modifications (Jakobsen et al. 1992). After drying the substrate at $40^{\circ} \mathrm{C}$ for $48 \mathrm{~h}$, homogenous subsamples were placed in distilled $\mathrm{H}_{2} \mathrm{O}$, extra-radical hyphae were detached from the substrate by adding sodium hexametaphosphate ( $35 \mathrm{~g} / \mathrm{liter})$ for $30 \mathrm{~min}$, and samples were filtered $\left(40 \mu \mathrm{m}\right.$ sieve, Retsch) and redissolved in $\mathrm{H}_{2} \mathrm{O}$. After $5 \mathrm{~s}$ of shaking and $1 \mathrm{~min}$ of sedimentation, a subsample of the solution was taken from a defined height, was filtered through a $0.45-\mu \mathrm{m}$ filter (filtration system, Merck Millipore, Darmstadt, Germany), and was stained with trypan blue (discussed above). Extra-radical hyphae length was calculated after microscopically counting intersects with ocular crosslines of at least 200 stops and averaging across several subsamples, as in Schweiger and associates (2014a).

\section{Leaf total $P, C$, and $\mathrm{N}$ analyses.}

For determination of the total foliar P content, leaf powder was mineralized via wet ashing including a pretreatment with $65 \% \mathrm{HNO}_{3}$ for $24 \mathrm{~h}$, followed by boiling with $65 \% \mathrm{HNO}_{3}$, and subsequently, $60 \% \mathrm{HClO}_{4}$ at $200^{\circ} \mathrm{C}$. After addition of $800-\mu \mathrm{l}$ Millipore $\mathrm{H}_{2} \mathrm{O}, \mathrm{PO}_{4}{ }^{3-}$ concentrations were assessed photometrically at $690 \mathrm{~nm}$, averaging duplicate or triplicate measurements, and using a $\mathrm{KH}_{2} \mathrm{PO}_{4}$ calibration curve (colorimetric ortho- $\mathrm{PO}_{4}{ }^{3-}$ test 1-78; Macherey-Nagel, Düren, Germany). Foliar $\mathrm{C}$ and $\mathrm{N}$ contents were determined via a $\mathrm{C} / \mathrm{N}$ analyzer (Vario MICRO Cube; Elementar Analysensysteme, Hanau, Germany) after high-temperature combustion.

\section{Metabolite profiling.}

Targeted metabolite profiling of primary metabolites (carbohydrates, organic acids, amino acids, sugar alcohols) was performed using GC-MS according to Kutyniok and Müller (2012) and Schweiger and associates (2014b). After extraction of leaf powder in 2:5:2 chloroform/methanol/water (chloroform HPLC grade: AppliChem, Darmstadt, Germany; methanol LCMS grade: Fisher Scientific, Loughborough, U.K.) containing the internal standard ribitol (99\%; Sigma-Aldrich), aliquots of the aqueous phases were dried under $\mathrm{N}_{2}$. Following derivatization (sequential methoximation and silylation at $37^{\circ} \mathrm{C}$ for 60 and 30 min, respectively), samples were analyzed with a Focus GC-DSQII (Thermo Electron, Rodano, Italy), separating metabolites on a VF-5 ms column $(30 \mathrm{~m} \times 0.25 \mathrm{~mm}$ i.d., $10-\mathrm{m}$ guard column; Varian, Palo Alto, CA, U.S.A.). The helium

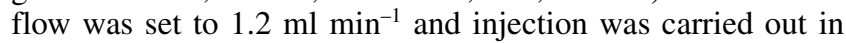
1:10 split mode at $225^{\circ} \mathrm{C}$ with a transfer line temperature of $250^{\circ} \mathrm{C}$. The oven was set to $80^{\circ} \mathrm{C}$ for $3 \mathrm{~min}$, and then, was ramped $5^{\circ} \mathrm{C} \mathrm{min}^{-1}$ to $325^{\circ} \mathrm{C}$. Using an electron impact positive ionization mode at $70 \mathrm{eV}$, masses from 50 to $750 \mathrm{~m} / \mathrm{z}$ were detected in full scan mode. Reference substances (from SigmaAldrich, AppliChem, Merck [Darmstadt, Germany], Roth [Karlsruhe, Germany], Macherey-Nagel) and n-alkanes (C8C40; Sigma-Aldrich) were additionally measured and retention indices (RI; Kováts 1958) were calculated. Blank samples without biological material were measured as well. Metabolites were identified by comparing their RI, mass spectra, and characteristic $\mathrm{m} / \mathrm{z}$ values (mass to charge) to reference standards, the Golm metabolome database (Hummel et al. 2010; Kopka et al. 2005), and mass spectral and retention time index libraries (Schauer et al. 2005). Peaks absent in the blanks and with a signal-to-noise ratio $>3$ were quantified as peak areas and were related to the area of the internal standard ribitol, using Xcalibur (Version 1.4. SR1; Thermo Electron). Further peaks that could not be identified were included in the metabolic fingerprinting data.

\section{Metabolic fingerprinting.}

Untargeted metabolic fingerprinting of the polar foliar metabolome was performed via uHPLC-ToF-MS (1290 Infinity uHPLC and 6210 ToF; Agilent Technologies, Santa Clara, CA, U.S.A.) as described earlier (Schweiger et al. 2014a and b). After threefold extraction of leaf powder in $90 \%$ methanol $\left(4^{\circ} \mathrm{C}\right)$ with hydrocortisone ( $>98 \%$; Sigma-Aldrich) as internal standard $(\mathrm{pH} \mathrm{7)}$ on ice, compounds were separated on a C18 column (Kinetex XB-C18, $150 \times 2.1 \mathrm{~mm}, 1.7 \mu \mathrm{m}$, with guard column; Phenomenex, Torrance, CA, U.S.A.) at $45^{\circ} \mathrm{C}$. A gradient from eluent A (water with $0.1 \%$ formic acid [pro analysis, eluent additive for LC-MS, about 98\%; Sigma-Aldrich]) to eluent B (acetonitrile [LC-MS grade; Fisher Scientific] with $0.1 \%$ formic acid) was used at a flow rate of $0.6 \mathrm{ml} \mathrm{min}{ }^{-1}$, increasing from 2 to $30 \% \mathrm{~B}$ within $20 \mathrm{~min}$, from 30 to $75 \% \mathrm{~B}$ within 9 min, followed by column cleaning and equilibration steps. ToF parameters were set to negative electrospray ionization mode, $350^{\circ} \mathrm{C}$ gas temperature, $12 \mathrm{ml} \mathrm{min}^{-1}$ drying gas flow, 55 pounds-force per square inch gauge nebulizer pressure, $-140 \mathrm{~V}$ fragmentor voltage, $3,500 \mathrm{~V}$ capillary voltage, and $60 \mathrm{~V}$ skimmer voltage. Data storage was in centroid mode, including masses from 100 to $1,700 \mathrm{~m} / \mathrm{z}$. Blank samples without biological material were measured in between test samples. Data were exported from MassHunter Qualitative Analysis (version B.03.01; Agilent Technologies), using the deisotoping function. Peak picking, peak grouping, and retention time correction were done using $x \mathrm{cms}$ (Smith et al. 2006; Tautenhahn et al. 2008) in the open software R (version 2.15.2 [R Core Team 2012]), with the following parameter settings: xset ( method $=$ 'centWave', $p$ pm $=15$, profmethod $=$ 'bin', peakwidth $=\mathrm{c}[5,20]$, sntresh $=10$, prefilter $=\mathrm{c}[3,500]$, fitgauss $=$ TRUE), retcor (method $=$ 'obiwarp'), and group (bw $=5$, minfrac $=0.5$, mzwid $=0.015)$. Only peaks eluting within the first $28 \mathrm{~min}$ were included in further analyses. Their intensities were related to hydrocortisone, and only those peaks whose intensities were at least 100 times higher than the median average intensity in the blanks were used for further analyses. The prominent secondary metabolites of $P$. major, aucubin and verbascoside, were identified by comparison of their retention times and accurate masses to references ( $>99 \%$; Phytoplan, Heidelberg, Germany).

Data from GC-MS and uHPLC-ToF-MS analyses were merged. Thereby, only those metabolic features were retained that were present in at least half of the replicates of one (Time $\times$ Treatment) group. Peak intensities were related to sample dry weights and $\log _{10}$ (peak intensity +1 ) transformed. Due to technical problems with the analytical platforms, four samples had to be discarded, decreasing sample sizes of groups T1 (PNM), T2 (NM), T2 (AM), and T3 (PNM) to $n=9$.

\section{Chlorophyll fluorescence and photosynthetic gas exchange measurements.}

Measurements of chlorophyll fluorescence and gas exchange were combined to obtain complementary information on plant photosynthetic performance. Parameters were measured on the youngest leaf of each plant at $\mathrm{T} 1$ and again at the same, further developed leaf at T2 and T3, under ambient conditions in the 
climate chamber in the afternoon hours. Chlorophyll fluorescence $(\mathrm{F})$ was measured with a pulse-amplitude-modulation fluorometer (Mini-PAM; Walz, Effeltrich, Germany). The maximum quantum yield of photosystem II (PS II) $\mathrm{F}_{\mathrm{v}} / \mathrm{F}_{\mathrm{m}}=\left(\mathrm{F}_{\mathrm{m}}-\right.$ $\left.\mathrm{F}_{0}\right) / \mathrm{F}_{\mathrm{m}}\left(\mathrm{F}_{\mathrm{v}}\right.$, variable fluorescence; $\mathrm{F}_{0}$, minimal fluorescence with all PS II centers open; $F_{m}$, maximal fluorescence with all PS II centers closed) was determined under reduced measuring light intensity in burst mode after leaves were dark-adapted with leaf clips for $10 \mathrm{~min}$. The effective quantum yield (Genty parameter) $\Delta \mathrm{F} / \mathrm{F}_{\mathrm{m}^{\prime}}=\left(\mathrm{F}_{\mathrm{m}^{\prime}}-\mathrm{F}\right) / \mathrm{F}_{\mathrm{m}^{\prime}}(\mathrm{F}$, fluorescence briefly before saturation pulse; $F_{m^{\prime}}$, maximal fluorescence with all PS II centers closed) and apparent ETR were assessed under adjusted measuring light intensity at a leaf temperature of $21.9 \pm$ $1.3^{\circ} \mathrm{C}$ and an actinic light of $202.6 \pm 10.8 \mu \mathrm{mol} \mathrm{m}{ }^{-2} \mathrm{~s}^{-1}$ PAR (mean \pm standard deviation), using a leaf-clip holder under steady-state conditions. The $\mathrm{CO}_{2}$ assimilation rate (A) and transpiration rate $(\mathrm{E})$ were determined with a gas exchange fluorescence system (GFS-3000; Walz) and were related to the respective leaf area. The following settings were applied: impeller intensity $=7,200 \mu \mathrm{mol} \mathrm{m} \mathrm{m}^{-2} \mathrm{~s}^{-1} \mathrm{PAR}$ in cuvette, $20^{\circ} \mathrm{C}$

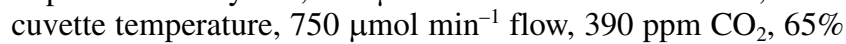
relative humidity. Cuvette zero points were taken hourly.

\section{Data mining and statistical analyses.}

Data analysis and statistics were performed according to a data mining strategy previously described (Schweiger et al. 2014a). If not stated otherwise, all statistical analyses were done in $\mathrm{R}$, using the packages base and stats. If the assumptions of normality (Shapiro-Wilk test) and homoscedasticity (Levene test, $\mathrm{R}$ package car) were not met, nonparametric statistics were used. Significance thresholds were set to $\alpha=0.05$ for all statistical tests. TRLC and extra-radical hyphae lengths of AM plants were compared between time points with a Kruskal-Wallis test (followed by a post hoc Kruskal mc test, R package pgirmess) and an ANOVA (post hoc Tukey honest significant difference [HSD] test), respectively. Plant biomass as well as foliar $\mathrm{P}, \mathrm{C}$, and $\mathrm{N}$ contents were modeled with generalized linear models (GLM) using Time (three levels: T1, T2, T3) and Treatment (three levels: NM, PNM, AM) as factors and allowing their interactions in the saturated model. Appropriate error structures and link functions were applied. Backward stepwise model simplification was done using Akaike's information criterion leading to the minimal adequate model, whose fit was assessed by diagnostics of deviance residuals and predicted values. To test for growth responses to $\mathrm{PO}_{4}{ }^{3-}$ supplementation or mycorrhization, user-defined orthogonal contrasts ( $\mathrm{R}$ package contrast) were set for pair-wise comparisons of plant biomass between time points (NM group: T2 versus T1, T3 versus T1) and the PNM as well as AM group versus the common NM control (for T1, T2, and T3 separately). To confirm that $\mathrm{PO}_{4}{ }^{3-}$ supplementation and mycorrhization increased the foliar $\mathrm{P}$ comparably, contrasts for leaf $\mathrm{P}$ content were set for comparisons between time points (NM group: T2 versus T1, T3 versus T1), the AM versus the PNM group (for T1, T2, and T3 separately) and the mean of the PNM and AM groups versus the NM group (for T1, T2, and T3). For C and $\mathrm{N}$, treatment contrasts using the factor level T1 (Time) as reference were calculated. The numbers of leaves and inflorescences per plant were compared between the treatment groups within each time point using Kruskal-Wallis tests.

To assess the influence of $\mathrm{PO}_{4}{ }^{3-}$ supplementation and mycorrhization on individual metabolic features, the intensity of each feature revealed from GC-MS and uHPLC-ToF-MS was compared between groups separately for each time point (effect of $\mathrm{PO}_{4}{ }^{3-}$ supplementation: PNM versus NM group; effect of mycorrhization: AM versus NM group). Fold changes were calculated as mean intensities in PNM and AM plants, respectively, compared with NM plants and were $\log _{2}$ scaled for symmetry (negative values: decrease in metabolite pool size; positive values: increase in pool size). A cluster heatmap was constructed using average linkage hierarchical clustering with Pearson's correlation distance matrices clustering both over groups (Time $\times$ Treatment) and metabolic features with Cluster 3.0 (de Hoon et al. 2004) and JavaTreeView (Saldanha 2004). Chemical traits occurring only in NM, PNM, or AM plants, i.e., features changed in a qualitative manner $(<2 \%$ of the metabolic features), were set to the maximum fold changes observed for other features. However, besides these basal assessments of decreases and increases of individual metabolic features under certain conditions, stringent selection criteria were set for a feature to be defined as modulated in a treatment-dependent manner. Hence, a feature was regarded as modulated by $\mathrm{PO}_{4}{ }^{3-}$ supplementation (PNM versus $\mathrm{NM}$ ) or mycorrhization (AM versus $\mathrm{NM}$ ) if its intensity significantly differed between the two groups (Mann Whitney- $U$ tests) and if its fold change was $<0.67$ (decrease in metabolite pool size; $<-0.58$ on $\log _{2}$ scale) or $>1.5$ (increase in pool size; $>0.58$ on $\log _{2}$ scale). Only quantitatively modified features, i.e., those occurring in both groups under consideration, were included. $P$ values were adjusted according to Benjamini and Hochberg (1995) at a false discovery rate of 0.05 to account for multiple testing. However, both unadjusted and adjusted $P$ values are given because, due to the high number of features, $P$ value corrections are highly conservative. Volcano plots (Cui and Churchill 2003) were plotted in MATLAB (7.10.0.499; The MathWorks, Natick, MA, U.S.A.) and $X^{2}$ tests were done to assess whether the numbers of features with decreased versus increased pool sizes significantly deviated from a uniform distribution. To determine the overlap of features modulated by both $\mathrm{PO}_{4}{ }^{3-}$ supplementation and $\mathrm{AM}$, area-proportional Venn/Euler diagrams were constructed $(\mathrm{R}$ package venneuler) for each time point. $F_{v} / F_{m}, \Delta F / F_{m^{\prime}}$, ETR, $\mathrm{A}$, and $\mathrm{E}$ were compared between NM, PNM, and AM plants within each time point, using ANOVA followed by post hoc Tukey HSD tests or Kruskal-Wallis tests followed by post hoc Kruskal mc tests.

\section{ACKNOWLEDGMENTS}

We thank K. Niehaus for providing references of various metabolites, J. Jarczak and F. Lansing for practical help in the lab, W. Beyschlag for making a Mini-PAM and GFS-3000 available for our measurements, S. Gerth for drawing the theoretical framework (Fig. 6), and I. Höpfner for fruitful discussions of the photosynthesis data. R. Schweiger, M. Baier, and C. Müller designed the study, R. Schweiger carried out the metabolome analyses, chlorophyll fluorescence, and gas exchange measurements, and analyzed the data, R. Schweiger, M. Baier, and C. Müller interpreted the data and wrote the manuscript.

\section{LITERATURE CITED}

Baas, R., and Lambers, H. 1988. Effects of vesicular-arbuscular mycorrhizal infection and phosphate on Plantago major ssp. pleiosperma in relation to the internal phosphate concentration. Physiol. Plantarum 74:701-707.

Benjamini, Y., and Hochberg, Y. 1995. Controlling the false discovery rate: A practical and powerful approach to multiple testing. J. R. Stat. Soc. 57:289-300.

Bi, H., Song, Y., and Zeng, R. 2007. Biochemical and molecular responses of host plants to mycorrhizal infection and their roles in plant defence. Allelopathy J. 20:15-28.

Björkman, O., and Demmig, B. 1987. Photon yield of $\mathrm{O}_{2}$ evolution and chlorophyll fluorescence characteristics at $77 \mathrm{~K}$ among vascular plants of diverse origins. Planta 170:489-504.

Black, K. G., Mitchell, D. T., and Osborne, B. A. 2000. Effect of mycorrhizal-enhanced phosphate status on carbon partitioning, translocation and photosynthesis in cucumber. Plant Cell Environ. 23:797-809.

Brechenmacher, L., Weidmann, S., van Tuinen, D., Chatagnier, O., Gianinazzi, S., Franken, P., and Gianinazzi-Pearson, V. 2004. Expression profiling of up-regulated plant and fungal genes in early and late 
stages of Medicago truncatula - Glomus mosseae interactions. Mycorrhiza 14:253-262.

Bundy, J. G., Davey, M. P., and Viant, M. R. 2009. Environmental metabolomics: A critical review and future perspectives. Metabolomics 5:3-21.

Copetta, A., Lingua, G., and Berta, G. 2006. Effects of three AM fungi on growth, distribution of glandular hairs, and essential oil production in Ocimum basilicum L. var. Genovese. Mycorrhiza 16:485-494.

Cui, X., and Churchill, G. A. 2003. Statistical tests for differential expression in cDNA microarray experiments. Genome Biology 4:210-220.

de Hoon, M. J. L., Imoto, S., Nolan, J., and Miyano, S. 2004. Open source clustering software. Bioinformatics 20:1453-1454.

Fester, T., Fetzer, I., Buchert, S., Lucas, R., Rillig, M. C., and Härtig, C. 2011. Towards a systemic metabolic signature of the arbuscular mycorrhizal interaction. Oecologia 167:913-924.

Fiehn, O. 2002. Metabolomics-The link between genotypes and phenotypes. Plant Mol. Biol. 48:155-171.

Gianinazzi, S., Gollotte, A., Binet, M. N., van Tuinen, D., Redecker, D. and Wipf, D. 2010. Agroecology: The key role of arbuscular mycorrhizas in ecosystem services. Mycorrhiza 20:519-530.

Giovannetti, M., and Mosse, B. 1980. An evaluation of techniques for measuring vesicular arbuscular mycorrhizal infection in roots. New Phytol. 84:489-500.

Harrison, M. J., and Dixon, R. A. 1993. Isoflavonoid accumulation and expression of defense gene transcripts during the establishment of vesicular-arbuscular mycorrhizal associations in roots of Medicago truncatula. Mol. Plant Microbe In. 6:643-654.

Hoagland, D. R., and Arnon, D. I. 1950. The water-culture method for growing plants without soil. Pages 1-32 in: California Agricultural Experiment Station Circular. Springer Verlag, Berlin.

Hummel, J., Strehmel, N., Selbig, J., Walther, D., and Kopka, J. 2010. Decision tree supported substructure prediction of metabolites from GCMS profiles. Metabolomics 6:322-333.

Jakobsen, I., Abbott, L. K., and Robson, A. D. 1992. External hyphae of vesicular-arbuscular mycorrhizal fungi associated with Trifolium subterraneum L. 1. Spread of hyphae and phosphorus inflow into roots. New Phytol. 120:371-380.

Kapoor, R., Chaudhary, V., and Bhatnagar, A. K. 2007. Effects of arbuscular mycorrhiza and phosphorus application on artemisin concentration in Artemisia annua L. Mycorrhiza 17:581-587.

Karagiannidis, N., Thomidis, T., Panou-Filotheou, E., and Karagiannidou, C. 2012. Response of three mint and two oregano species to Glomus etunicatum inoculation. Aust. J. Crop Sci. 6:164-169.

Karandashov, V., and Bucher, M. 2005. Symbiotic phosphate transport in arbuscular mycorrhizas. Trends Plant Sci. 10:22-29.

Kaschuk, G., Kuyper, T. W., Leffelaar, P. A., Hungria, M., and Giller, K. E. 2009. Are the rates of photosynthesis stimulated by the carbon sink strength of rhizobial and arbuscular mycorrhizal symbioses? Soil Biol. Biochem. 41:1233-1244.

Khaosaad, T., Vierheilig, H., Nell, M., Zitterl-Eglseer, K., and Novak, J. 2006. Arbuscular mycorrhiza alter the concentration of essential oils in oregano (Origanum sp., Lamiaceae). Mycorrhiza 16:443-446.

Kopka, J., Schauer, N., Krueger, S., Birkemeyer, C., Usadel, B., Bergmuller, E., Dormann, P., Weckwerth, W., Gibon, Y., Stitt, M., Willmitzer, L., Fernie, A. R., and Steinhauser, D. 2005. GMD@CSB.DB: The Golm Metabolome Database. Bioinformatics 21:1635-1638.

Koricheva, J., Gange, A. C., and Jones, T. 2009. Effects of mycorrhizal fungi on insect herbivores: A meta-analysis. Ecology 90:2088-2097.

Kováts, E. 1958. Gaschromatographische Charakterisierung organischer Verbindungen. 1. Retentionsindices aliphatischer Halogenide, Alkohole, Aldehyde und Ketone. Helv. Chim. Acta 41:1915-1932.

Kutyniok, M., and Müller, C. 2012. Crosstalk between above- and belowground herbivores is mediated by minute metabolic responses of the host Arabidopsis thaliana. J. Exp. Bot. 63:6199-6210.

Liu, J. Y., Blaylock, L. A., Endre, G., Cho, J., Town, C. D., VandenBosch, K. A., and Harrison, M. J. 2003. Transcript profiling coupled with spatial expression analyses reveals genes involved in distinct developmental stages of an arbuscular mycorrhizal symbiosis. Plant Cell 15:2106-2123.

Liu, H. L., Tan, Y., Nell, M., Zitter-Eglseer, K., Wawscrah, C., Kopp, B., Wang, S. M., and Novak, J. 2014. Arbuscular mycorrhizal fungal colonization of Glycyrrhiza glabra roots enhances plant biomass, phosphorus uptake and concentration of root secondary metabolites. J. Arid Land 6:186-194.
Martín-Rodríguez, J., León-Morcillo, R., Vierheilig, H., Ocampo, J. A., Ludwig-Müller, J., and García-Garrido, J. M. 2011. Ethylene-dependent/ethylene-independent ABA regulation of tomato plants colonized by arbuscular mycorrhiza fungi. New Phytol. 190:193-205.

Olsson, P. A., Rahm, J., and Aliasgharzad, N. 2010. Carbon dynamics in mycorrhizal symbioses is linked to carbon costs and phosphorus benefits. FEMS (Fed. Eur. Microbiol. Soc.) Microbiol. Ecol. 72:123-131.

Pankoke, H., Buschmann, T., and Müller, C. 2013. Role of plant $\beta$-glucosidases in the dual defense system of iridoid glycosides and their hydrolyzing enzymes in Plantago lanceolata and Plantago major. Phytochemistry 94:99-107.

Parniske, M. 2008. Arbuscular mycorrhiza: The mother of plant root endosymbioses. Nat. Rev. Microbiol. 6:763-775.

Rausch, C., and Bucher, M. 2002. Molecular mechanisms of phosphate transport in plants. Planta 216:23-37.

Saldanha, A.J. 2004. Java Treeview-Extensible visualization of microarray data. Bioinformatics 20:3246-3248.

Schauer, N., Steinhauser, D., Strelkov, S., Schomburg, D., Allison, G., Moritz, T., Lundgren, K., Roessner-Tunali, U., Forbes, M. G., Willmitzer, L., Fernie, A. R., and Kopka, J. 2005. GC-MS libraries for the rapid identification of metabolites in complex biological samples. FEBS (Fed. Eur. Biochem. Soc.) Lett. 579:1332-1337.

Schliemann, W., Ammer, C., and Strack, D. 2008. Metabolite profiling of mycorrhizal roots of Medicago truncatula. Phytochemistry 69:112-146.

Schüßler, A., and Walker, C. 2010. The Glomeromycota. A species list with new families and new genera. The Royal Botanic Garden Edinburgh, The Royal Botanic Garden Kew, Botanische Staatssammlung Munich, and Oregon State University, Gloucester.

Schweiger, R., Baier, M., Persicke, M., and Müller, C. 2014a. High specificity in plant leaf metabolic responses to arbuscular mycorrhiza. Nat. Commun. 5:3886.

Schweiger, R., Heise, A.-M., Persicke, M., and Müller, C. 2014b. Interactions between the jasmonic and salicylic acid pathway modulate the plant metabolome and affect herbivores of different feeding types. Plant Cell Environ. 37:1574-1585.

Shaul-Keinan, O., Gadkar, V., Ginzberg, I., Grunzweig, J. M., Chet, I., Elad, Y., Wininger, S., Belausov, E., Eshed, Y., Arzmon, N., Ben-Tal, Y., and Kapulnik, Y. 2002. Hormone concentrations in tobacco roots change during arbuscular mycorrhizal colonization with Glomus intraradices. New Phytol. 154:501-507.

Smith, S. E. 1982. Inflow of phosphate into mycorrhizal and non-mycorrhizal plants of Trifolium subterraneum at different levels of soil phosphate. New Phytol. 90:293-303.

Smith, S. E., Smith, F. A., and Jakobsen, I. 2004. Functional diversity in arbuscular mycorrhizal (AM) symbioses: The contribution of the mycorrhizal $\mathrm{P}$ uptake pathway is not correlated with mycorrhizal responses in growth or total P uptake. New Phytol. 162:511-524.

Smith, C. A., Want, E. J., O’Maille, G., Abagyan, R., and Siuzdak, G. 2006. XCMS: Processing mass spectrometry data for metabolite profiling using nonlinear peak alignment, matching, and identification. Anal. Chem. 78:779-787.

Strack, D., Fester, T., Hause, B., Schliemann, W., and Walter, M. H. 2003. Arbuscular mycorrhiza: Biological, chemical, and molecular aspects. J. Chem. Ecol. 29:1955-1979.

Stribley, D. P., Tinker, P. B., and Rayner, J. H. 1980. Relation of internal phosphorus concentration and plant weight in plants infected by vesicular-arbuscular mycorrhizas. New Phytol. 86:261-266.

Tautenhahn, R., Böttcher, C., and Neumann, S. 2008. Highly sensitive feature detection for high resolution LC/MS. BMC Bioinformatics 9:504.

Toussaint, J. P. 2007. Investigating physiological changes in the aerial parts of AM plants: What do we know and where should we be heading? Mycorrhiza 17:349-353.

Toussaint, J. P., Smith, F. A., and Smith, S. E. 2007. Arbuscular mycorrhizal fungi can induce the production of phytochemicals in sweet basil irrespective of phosphorus nutrition. Mycorrhiza 17:291-297.

Zhang, B. B., Liu, W. Z., Chang, S. X., and Anyia, A. O. 2012. Phosphorus fertilization and fungal inoculations affected the physiology, phosphorus uptake and growth of spring wheat under rainfed conditions on the Canadian prairies. J. Agron. Crop Sci. 199:85-93.

Zubek, S., Mielcarek, S., and Turnau, K. 2012. Hypericin and pseudohypericin concentrations of a valuable medicinal plant Hypericum perfor atum L. are enhanced by mycorrhizal fungi. Mycorrhiza 22:149-156. 